Vietnam Academy of Science and Technology
Vietnam Journal of Earth Sciences
http://www.vjs.ac.vn/index.php/jse

\title{
Methodology of determining effective porosity and longi- tudinal dispersivity of aquifer and the application to field tracer injection test in Southern Hanoi, Vietnam
}

\author{
Tong Ngoc Thanh1, Trieu Duc Huy', Nguyen Van Kenh¹, Tong Thanh Tung1, \\ Pham Ba Quyen ${ }^{1}$, Nguyen Van Hoang2* \\ ${ }^{1}$ Vietnam National Center for Water Resources Planning and Investigation \\ ${ }^{2}$ Institute of Geological Sciences, Vietnam Academy of Science and Technology
}

Received 21 November 2016. Accepted 8 February 2017

\begin{abstract}
Groundwater field pumping out and tracer injection test had been carried out at Nghiem Xuyen commune, Thuong Tin district, Hanoi where salinized and fresh groundwater boundary exist in the Pleistocene aquifer. The test was executed with pumping out rate of $91 / \mathrm{sec}$ and tracer injection rate of $0.71 / \mathrm{sec}$ of water with the salt concentration of $5 \mathrm{~g} / 1$. The interpretation and analysis of the groundwater solute transport parameters by the field pumping out and tracer injection test is a rather complicated and delicate task due to the variability of the temporal boundary conditions. The test results have shown that although the tracer injection time is rather long (up to 60 hours), the tracer breakthrough curve of the tracer concentration of the pumped out water has its very specific characteristic shape, however with some variation due to the test invisible variability of conditions. The results of the parameter identification based on the method of least squares have given effective porosity of 0.32 and longitudinal dispersivity of $2.5 \mathrm{~m}$ (which give the hydrodynamic dispersion of from $\mathrm{D}=250 \mathrm{~m}^{2} /$ day right outside the pumping well screen to $\mathrm{D}=18 \mathrm{~m}^{2} /$ day right outside the injection well screen). The minimal sum of squares of the differences between the observed and model normalized tracer concentration is 0.00119 , which is corresponding to the average absolute difference between observed and model normalized concentrations of 0.0355 (while 1 is the worse and 0 is the best). The results have also shown that the maximal tracer concentration right outside the pumping out well screen is 6.1 times greater than the tracer concentration of the pumped out water. The distortion flow coefficient $\alpha \mathrm{W}$ (the ratio between the flow rate through the injection well section without its presence) and the groundwater flow into the tracer injection well is from 18.66 (at the early testing time) to 10.76 (at the later testing time).
\end{abstract}

Keywords: Groundwater solute transport, tracer injection, effective porosity, longitudinal dispersivity, method of least squares, flow distortion coefficient.

(C)2017 Vietnam Academy of Science and Technology

\section{Introduction}

Groundwater (GW) from Pleistocene aquifer in Hanoi had been being exploited for dif-

"Corresponding author, Email: n_v_hoang_vdc@yahoo.com ferent uses since the late of 19th century, and still plays a leading role in the city's water supply. With the GW exploitation time and exploitation expansion, the cone of GW level depression is getting larger and approaching 
the boundary with brackish in the southern of Hanoi city, in Thuong Tin district (Trieu Duc Huy, 2015). The pumping out and salt (hereafter called a tracer or solute in concrete context) solution injection testing at the experimental well system CHN5 had been conducted to determine the solute transport parameters of the lower Pleistocene aquifer, namely the effective porosity neff and longitudinal dispersivity aL of the aquifer. These parameters are needed for the modeling prediction of approaching of brackish groundwater in the Southern Hanoi (Figure 1) towards the center of Hanoi city where GW pumping fields are located. The map showing the fresh and brackish GW in the Pleistocene in the area in the Southern Hanoi is shown in Figure 2.

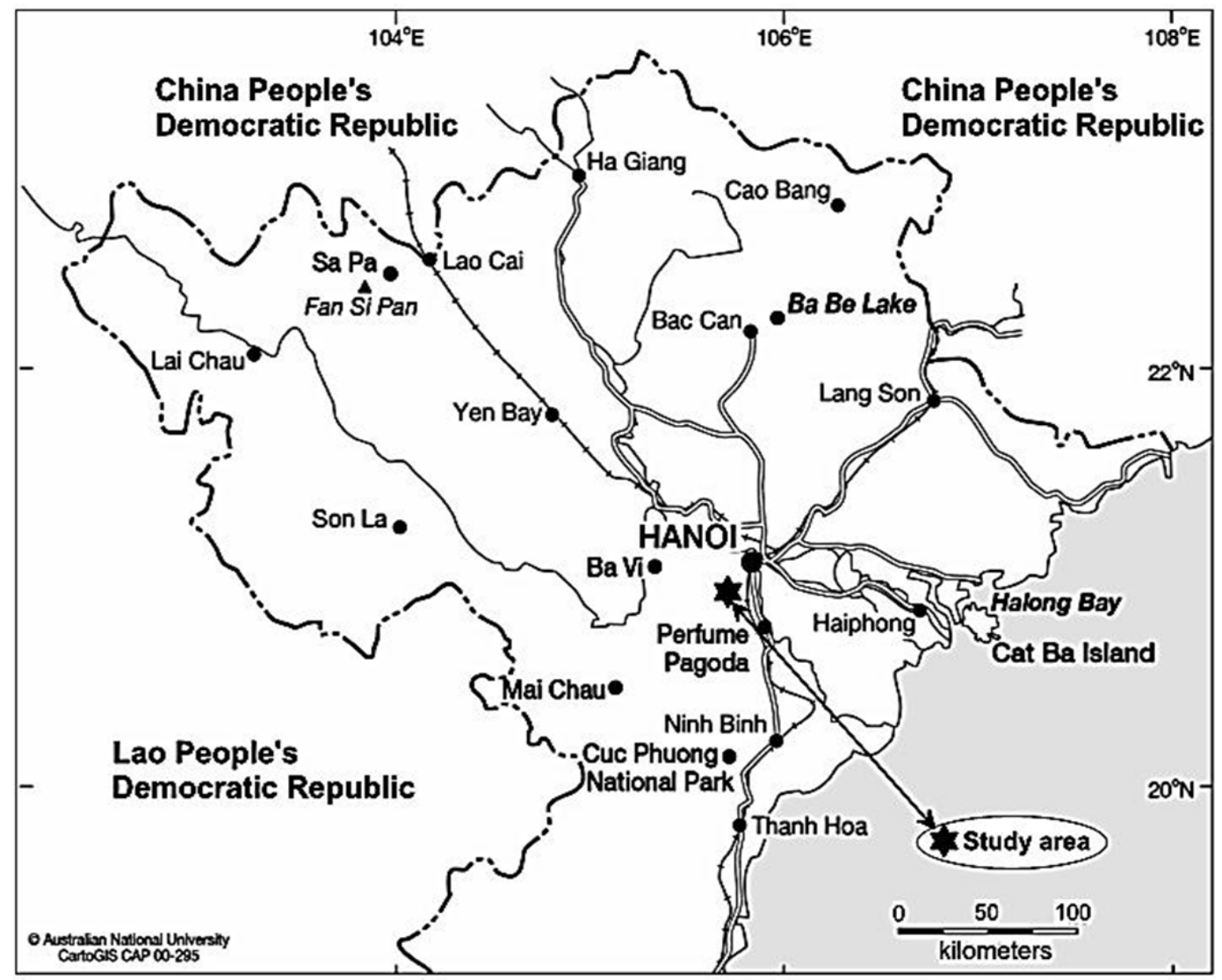

Figure 1. Map of location of study area

There are two groups of testing for determining GW solute transport parameters: laboratory and field testing. Regardless a laboratory or field testing is conducted, the testing requires a long testing time, i.e. a rather high expense. Without paying attention to the required reliability of the obtained values of the parame- ters, the laboratory testing may last very long to have sufficient data set for parameter analysis with only insignificant expense increase, while the prolongation of the field testing would remarkably increase the expense. Therefore, an initial proper design of the experimental well locations, the design of pumping out and salt 
solution injection rates for selected testing time frame would be very important to ensure a successful parameter analysis with the experimentally obtained data set.

The paper presents how to design a reasonable testing well system for pumping out and salt solution injection testing in Pleistocene aquifer in Nghiem Xuyen commune, Thuong Tin district, Hanoi city for determining the aquifer hydrogeological parameters and solute transport parameters with the utilization of finite element (FE) modeling (FEM) of the GW solute transport by advection-dispersion in the implementation of the project "Groundwater protection in great cities (city: Hanoi)" (Trieu Duc Huy, 2015).

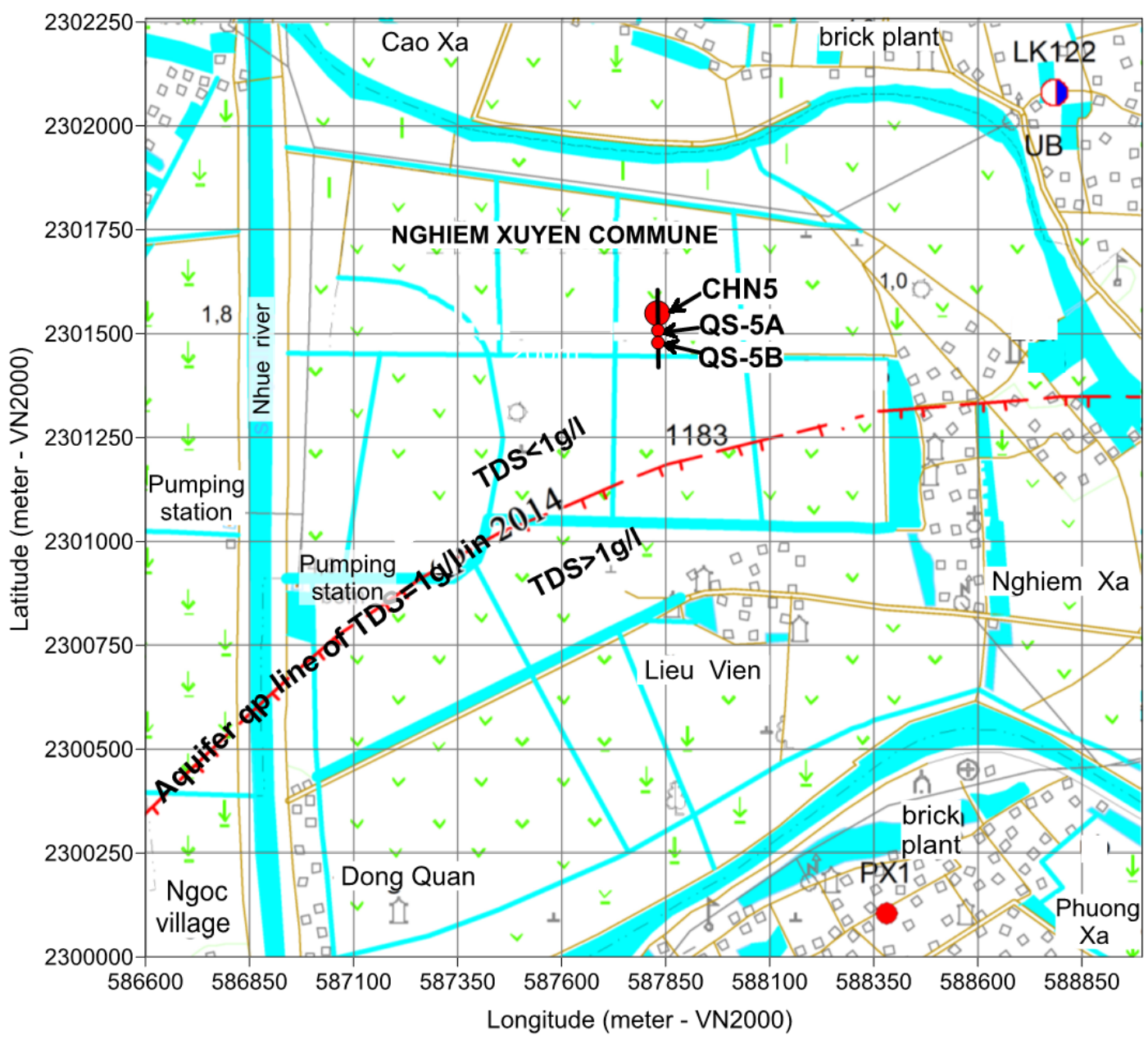

Figure 2. Field testing wells' location and Pleistocene aquifer fresh-brackish boundary

2. Local hydrogeological units, testing wells' scheme and testing data

\subsection{Hydrogeological units}

The following are the hydrogeological units present in the study area from top to bottom:

- Holocene aquifer (qh) is continuously existing in the area. The top of the aquifer is in 
the depth $4-5 \mathrm{~m}$ and the bottom is in the depth $40 \mathrm{~m}-44 \mathrm{~m}$. The aquifer mainly consists of sands and silty sands. Overlying the aquifer is a low permeable layer consisting clay and silty clay of $2.8-5 \mathrm{~m}$ thickness.

A low permeable layer of Vinh Phuc formation (Q13vp) with thickness $2 \div 8 \mathrm{~m}$. This layer is absent only in one place.

Pleistocene aquifer (qp): the depth of the top is $43 \div 52 \mathrm{~m}$ and the depth of the bottom is $64 \div 69 \mathrm{~m}$. This aquifer is usually divided into two sub-aquifers: qp2 on the upper part and qp1 in the lower part, which are separated by an impermeable layer of clay. The qp aquifer consists of pebbles and gravels with sands. The wells in the aquifer have pumping rates from $6.061 / \mathrm{s}$ to $12.331 / \mathrm{s}$. The aquifer transmissivity is from $80 \mathrm{~m}^{2} /$ day to $630 \mathrm{~m}^{2} /$ day.

The Quaternary aquifer hydraulic parameters and wells' data in the testing area are given in Table 1.

Fractured Neogene aquifer (N2) consisting of sandstone and conglomerate is underlying the qp1 sub-aquifer.

Table 1. Aquifer hydraulic parameters and wells' data in the testing area

\begin{tabular}{|c|c|c|c|c|c|}
\hline \multirow{2}{*}{ Well } & \multirow{2}{*}{ Aquifer } & \multicolumn{4}{|c|}{ Parameters } \\
\hline & & $Q(1 / \mathrm{s})$ & $s(\mathrm{~m})$ & $K(\mathrm{~m} /$ day $)$ & $K m\left(\mathrm{~m}^{2} /\right.$ day $)$ \\
\hline LK114 & $\mathrm{qh}$ & 3.33 & 2.54 & 12.19 & 210 \\
\hline LK140A & $q p$ & 13.2 & 7.88 & 20.71 & 290 \\
\hline LK141 & $q p$ & 12.62 & 1.03 & 70.00 & 1610 \\
\hline LK119A & $\mathrm{qh}$ & 3.84 & 1.15 & 9.20 & 260 \\
\hline LK120 & $q p$ & 11.48 & 0.78 & 152.00 & 1670 \\
\hline LK121 & $q p$ & 12.33 & 2.05 & 36.82 & 630 \\
\hline LK122 & $q p$ & 6.06 & 15.17 & 12.80 & 80 \\
\hline LK104 & $q p$ & 6.67 & 2.35 & 22.68 & 410 \\
\hline LK101 & $q p$ & 9.09 & 5.04 & 23.14 & 240 \\
\hline LK102 & $q p$ & 12.5 & 0.87 & 58.05 & 1680 \\
\hline LK103 & $\mathrm{qh}$ & 8.33 & 3.47 & 9.70 & 330 \\
\hline LK129 & $q p$ & 21.79 & 1.09 & 83.53 & 2510 \\
\hline LK110 & $q p$ & 7.82 & 4.04 & 18.28 & 210 \\
\hline LK130 & $\mathrm{gh}$ & 0.40 & 16.19 & & \\
\hline
\end{tabular}

2.2. Testing wells' scheme and obtained testing data

Based on the average thickness and effective porosity of the $\mathrm{qp}$ aquifer in the testing area and the approved testing time in the project proposal, the distances between the testing wells have been selected to be $8 \mathrm{~m}$ as shown in Figure 3: the pumping out central well CHN5 and the tracer solution injection well QS-5A, and observation well QS-5B for monitoring the possible approaching of the brackish GW. The drilling data have allowed constructing hydrogeological section through the wells (Figure 4) and well log (Figure 5) of the central well CHN5.

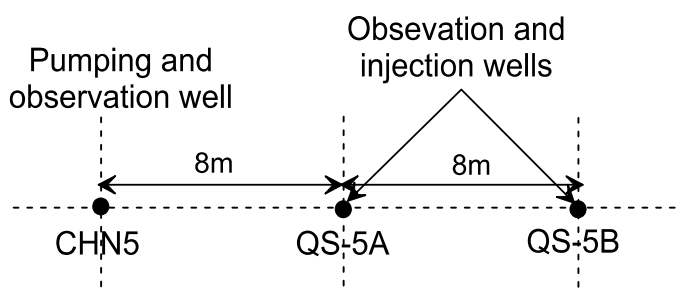

Figure 3. Plan of the testing wells

The central well CHN5 has the diameter of $200 \mathrm{~mm}$ and wells QS-5A and QS-5B have the diameter of $90 \mathrm{~mm}$. The testing aquifer is the lower Pleistocene aquifer qp1 in the depth from $55.05 \mathrm{~m}$ to $67.75 \mathrm{~m}$, i.e. the thickness is $12.7 \mathrm{~m}$ (Figure 5). The testing time is 60 hours. The pumping out and tracer solution injection started at the same time. Pumping rate is $2,592 \mathrm{~m}^{3} /$ day $(301 / \mathrm{s})$ and injection rate is $60.48 \mathrm{~m}^{3} /$ day $(0.71 / \mathrm{s})$, which is equal to $2.33 \%$ of the pumping rate. For those pumping and injection rates, the possible maximal TDS of the pumped out water would be $1.675 \mathrm{~g} / 1$ (the pumped out water has TDS increased $228 \%$ ) since the natural GW of the lower Pleistocene aquifer $\mathrm{qp} 1$ at the testing site has TDS of $0.51 \mathrm{~g} / 1$ and the injection salt solution is prepared by adding $5 \mathrm{~g}$ of salt in a liter of that GW. If the flow distortion coefficient $\alpha w$ has very high value, for example, 20 , then the TDS of the pumped out water would be $0.568 \mathrm{~g} / 1$ which is equivalent to TDS increase of $11.4 \%$, which is a good enough TDS change magnitude for analysis of the TDS breakthrough curve. The TDS of the water is always referred to the water temperature of $25^{\circ} \mathrm{C}$. The salt solution in the injection well is constantly well mixed over the entire well water column by continuous mixing the water column in the well. 
Vietnam Journal of Earth Sciences, 39(1), 58-75

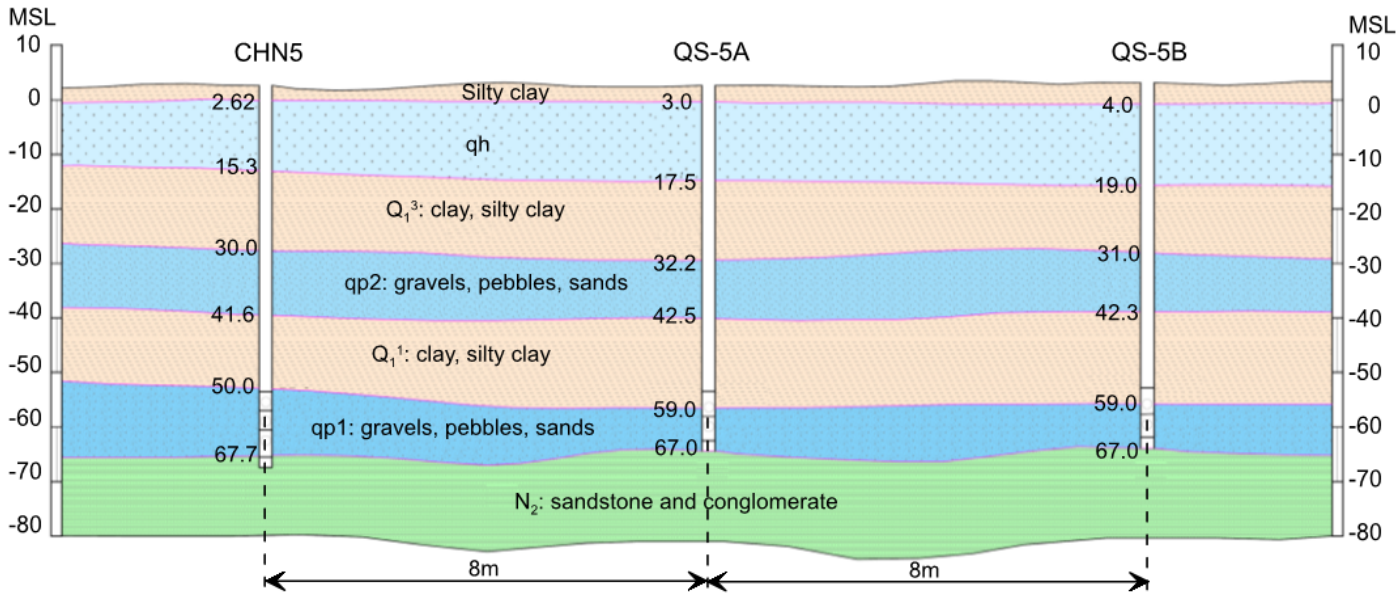

Figure 4. Hydrogeological section through the testing wells

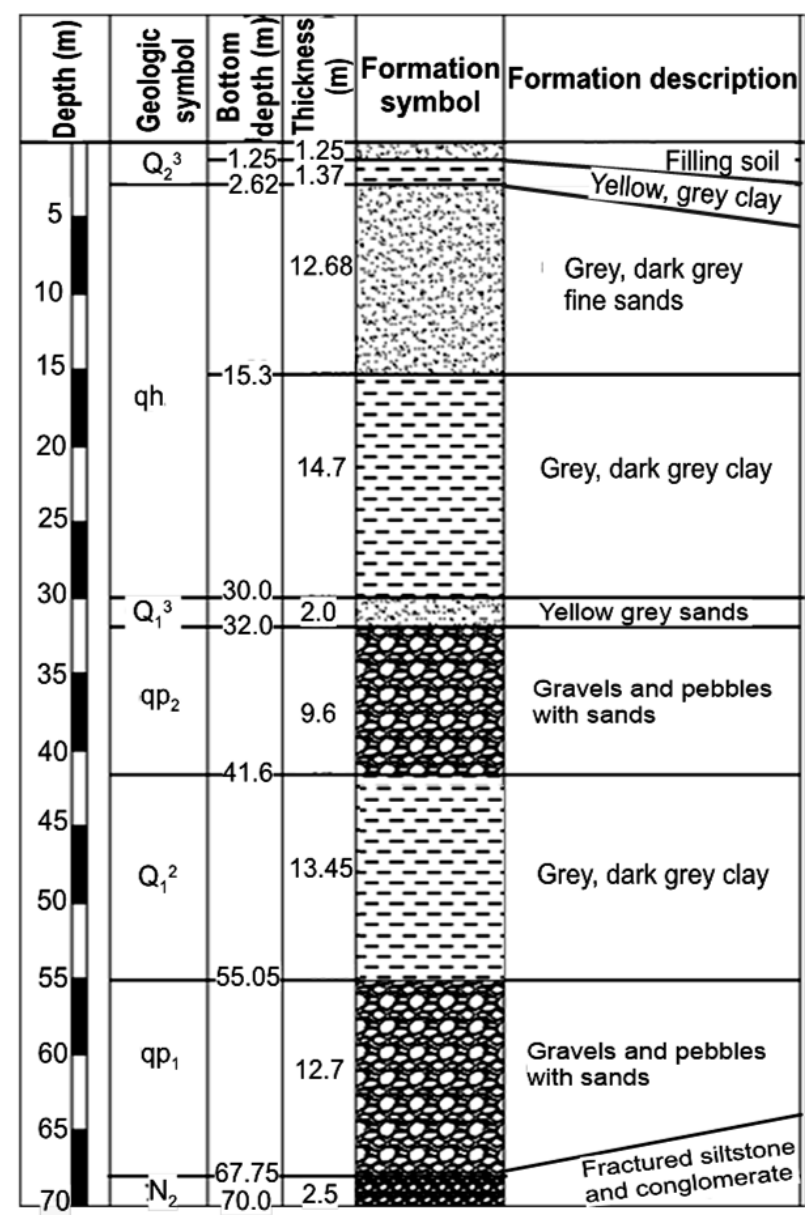

Figure 5. Well log of central well CHN5 
Tong Ngoc Thanh, et al./Vietnam Journal of Earth Sciences 39 (2017)

\subsection{Obtained testing data}

2015. The temporal TDS of the water inside the injection well is presented in Figure 6 and

The testing started at the $8 \mathrm{AM}$ the 11th Oct. that of the pumped out water is in Figure 7.

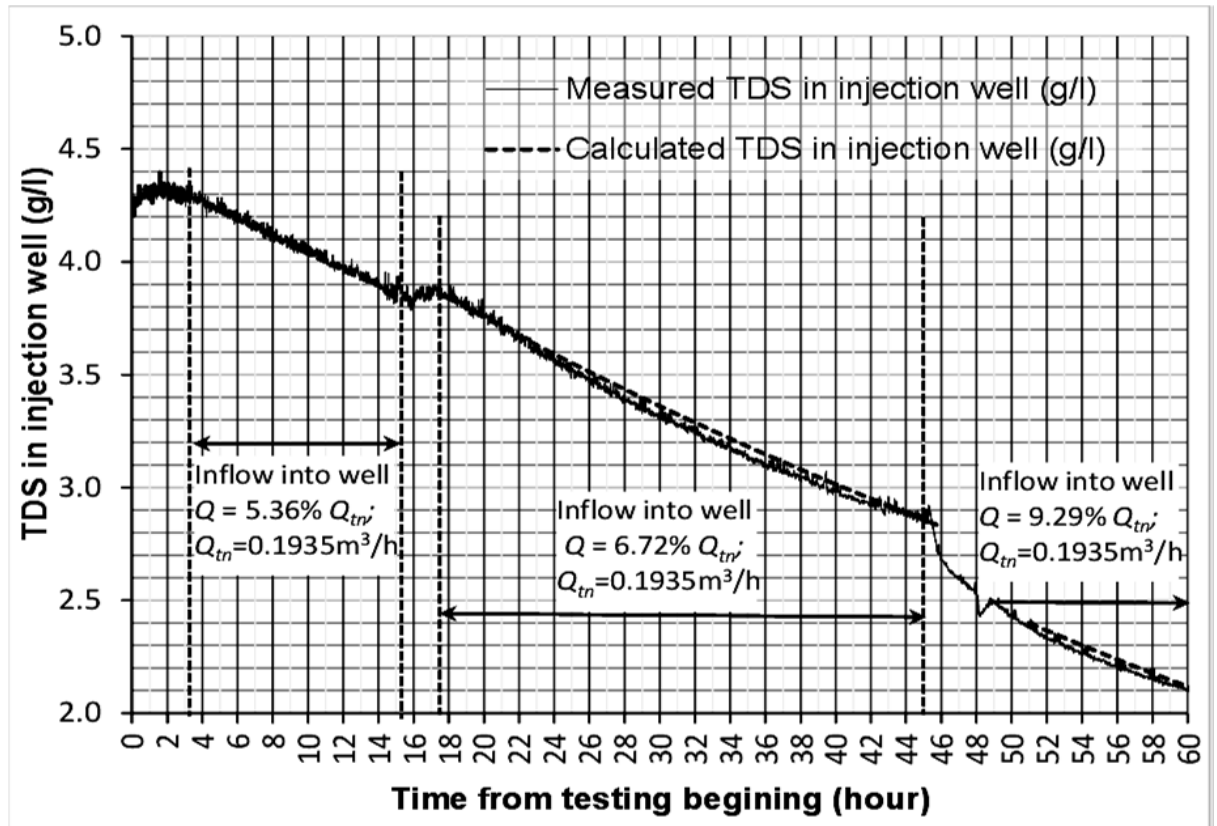

Figure 6. GW TDS in the injection well

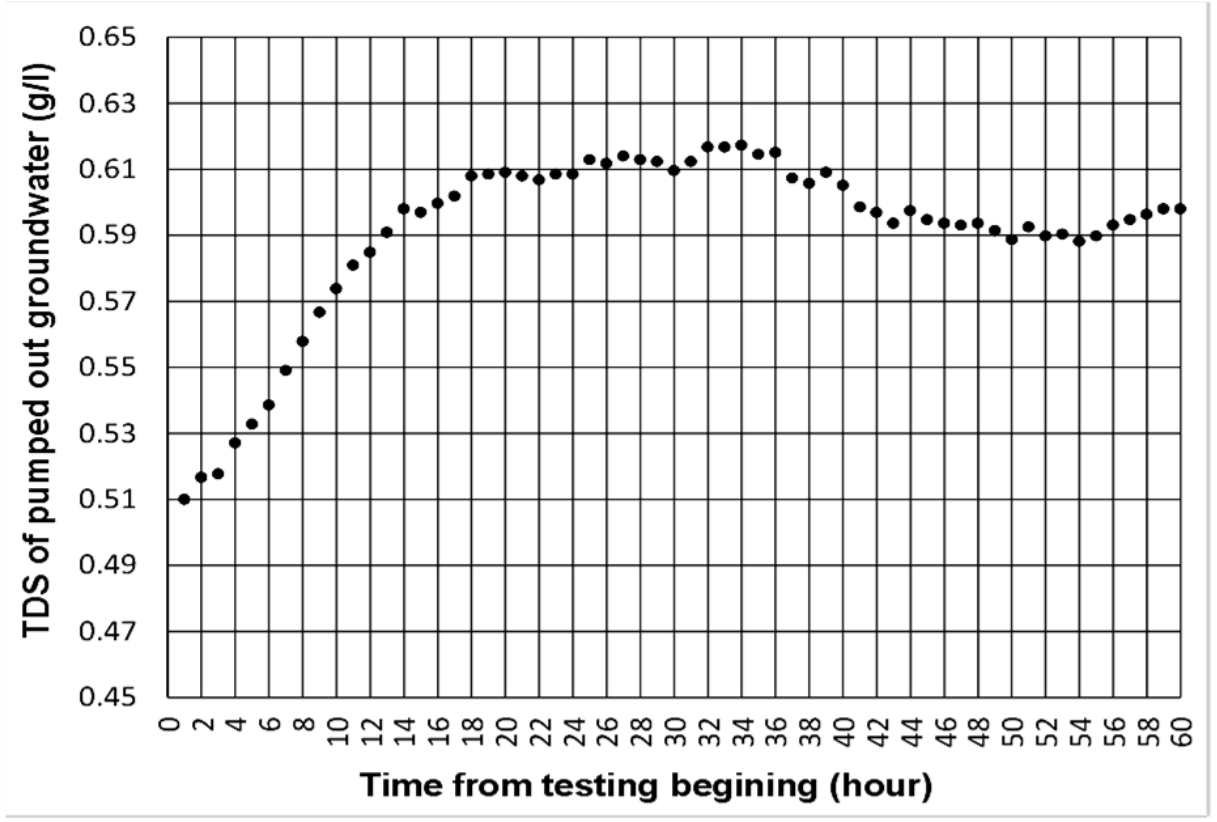

Figure 7. TDS of the pumped out GW 
Vietnam Journal of Earth Sciences, 39(1), 58-75

\subsection{Boundary condition at the outside injection well}

The solute transport boundary condition at the injection well can be interpreted differentially by different researchers in order to be able to solve the problem. Below is a description of how the boundary can be interpreted in two ways.

First kind of boundary condition (boundary of specified solute concentration):

In accordance to Drost et al. (1968) the solute concentration of $\mathrm{GW}$ around the injection well depends upon the flow rate through the well towards the pumping well and upon the solute solution injection regime, and can be considered as the specified solute concentration and determined by the following partial differential equation:

$-2 \alpha r_{I} n_{e f f} m\left|V\left(r_{L}\right)\right| C_{I}=\pi r_{I}^{2} b \frac{d C_{I}}{d t}-M ; C_{I}(0)=\frac{M_{0}}{\pi r_{I}^{2} b}(1)$

in which: $V\left(r_{L}\right)$ is the pore water velocity through the injection well towards the pumping well $(\mathrm{L} / \mathrm{T}) ; r_{L}$ is the distance between the injection and pumping wells. (L); $r_{I}$ is the tracer injection well's radius $(\mathrm{L}) ; m$ is the aquifer thickness (L); $b$ is the water column in the solute injection well (L); $M_{0}$ is the weight of the tracer mass injected into the well one time (M); $M$ is the weight of the tracer mass continuously injected into the well per unit of time $(\mathrm{M} / \mathrm{T})$; $t$ is the time $(\mathrm{T})$.

In case if the weight of the tracer mass injected into the well just only one time, then $M=0$, and in case if the weight of the tracer mass continuously injected into the well per unit of time then $M_{0}=0$, i.e. $C_{I}(0)=0$.

Second kind of boundary condition (boundary of specified solute flow rate):

In accordance to Novakowski (1992) the flow rate of solute mass in GW around the injection well can be considered as a specified value and determined by the following equation:

$$
q_{C}=-D_{r} \frac{\partial C}{\partial r}+V\left(r_{L}\right) C=V\left(r_{L}\right) C_{I}
$$

in which: $D_{r}$ is the hydrodynamic dispersion coefficient in the direction of GW flow $\left(\mathrm{L}^{2} / \mathrm{T}\right)$.

\section{Selected boundary condition in this work:}

The first kind of boundary condition had been selected to be used in this work: the specified solute concentration outside the screen of the injection well shall be determined in accordance to Eq.(1). For the case if the observation well does not cause any disturbance of the GW flow as that there is no well, then the GW flow through the well section is determined by the following equation:

$$
\left|V\left(r_{L}\right)\right|=\frac{2 Q r_{I}}{2 \pi r_{L}}: b n_{h h}=\frac{Q r_{I}}{b n_{h h} \pi r_{L}} ; \quad Q_{t n}=2 r_{I} b n_{h h}\left|V\left(r_{L}\right)\right|=\frac{2 Q r_{I}^{2}}{\pi r_{L}}
$$

in which: $Q$ is the pumping out rate from the central well $\left(\mathrm{M}^{3} / \mathrm{T}\right) ; r_{I}$ is the radius of the observation well (L); $r_{L}$ is the distance between the pumping well and observation well (L); $b$ is the aquifer thickness $(\mathrm{L}) ; n_{h h}$ is the effective porosity of the aquifer.

With the pumping out rate of $2,592 \mathrm{~m}^{3} /$ day and other relevant data as given above, the natural flow rate through the observation well is $Q_{t n}=0.1935 \mathrm{~m}^{3} / \mathrm{h}$. Due to the additional hydraulic resistance resulted from the observation well, the actual flow rate through the well is always smaller than the natural flow rate through the section equal to the observation well diameter given in Eq.(3) (Drost et al., 1968). The distortion flow coefficient $\alpha_{W}$ is defined as the ratio between the flow rate through the injection well section without its presence (Drost et al., 1968; Hall, 1996). As the TDS of the GW inside the injection well is measured, the GW flow rate $Q_{\text {well }}$ into and out the injection well can be determined by the following balance of the mixing of two volumes of water with two known TDS values: known volume of water inside the injection well with known TDS equal to $C^{l}$ well 
at time $t_{1}$, TDS equal to $C^{2}$ well at time $t_{2}=t_{1}+\Delta t$ and TDS of the natural GW equal to $C_{t n}$ :

$$
C_{\text {well }}^{2}=\frac{C_{\text {well }}^{1}\left(V_{\text {well }}-\Delta t Q_{\text {well }}\right)+C_{\text {tn }} Q_{\text {well }}}{V_{\text {well }}}
$$

Then the flow distortion coefficient $\alpha_{w}$ is the ration between $Q_{\text {well }}$ and $Q_{t n}$.

By Eq.(4) using the obtained measured TDS inside the injection well, the following results have been abtained (Figure 6):

From the 3.5th hour the 15.5th hour: $Q_{\text {well }}=0.0104 \mathrm{~m}^{3} / \mathrm{h}\left(\alpha_{w}=18.66\right)$;

From the 17.5th hour the 45th hour: $Q_{\text {well }}=0.0130 \mathrm{~m}^{3} / \mathrm{h}\left(\alpha_{w}=14.88\right)$;

From the 49th hour to the end of the testing: $Q_{\text {well }}=0.0178 \mathrm{~m}^{3} / \mathrm{h}\left(\alpha_{w}=10.76\right)$.

Brouyère (2008) had received $\alpha_{w}=11.50$ for a well of radius $0.025 \mathrm{~m}$.

\section{Proposed methodology for determining effecitive porosity and longitudinal dispersivity}

\subsection{The fundamentals}

The role of the effective porosity and hydrodynamic dispersion in the solute transport by GW can be illustrated in Figure 8 (Bear J. and Verruijt A., 1987). The GW pore velocity is inversely proportional to the effective porosity. After a pulse injection of a solute into the aquifer in the upstream area then at the distance $\mathrm{L}$ downstream of the injection point the maximal concentration of the solute is observed at the time $\mathrm{t}=\mathrm{L} /($ Vneff) (Figure 8b). Due to the hydrodynamic dispersion a plan ellipse ring of solute concentration is formed (Figure 8b). The hydrodynamic dispersion coefficient can only be determined by analytical approach for some completely homogeneous aquifer medium with simple initial and boundary conditions in one or two simple geometrical configurations. In reality, such ideal conditions do not exist so that numerical modeling is required for parameter identification. In the case of a continuous injection of solute in one dimensional flow condition in such a way that the solute concentration at the injection point is constant, then at the distance L downstream of the injection point a relative solute concentration of 0.5 is observed at the time $\mathrm{t}=\mathrm{L} /$ Vneff (Figure 8a).

Therefore, the data required for determination of GW solute transport parameters are breakthrough curves either in time and or in space or both. Such breakthrough curves must be obtained in the testings.

\subsection{Interpretation of the obtained tracer injection testing data}

The GW TDS breakthough curves for injection well and pumped out water are presented in Figure 8. The TDS of the GW in the pumping well started to increase very early since the 2nd hour and almost linearly increased until the 13th hour. The curve shows a stabilization trend at the 18th hour, which may mean that the advection time of the solute from the injection well to the pumping well is 18 hours. After 18 hours the solute concentration is varying till the 36th hour due to the most probable reason that the solute injection rate was not stable all the time. The solute concentration decreased from the 36th hour to 55th hour.

In the injection well, the solute concentration had an increasing trend from the 16th hour, which is corresponding to the maximal solute concentration in the pumping well at the 34th hour, which is corresponding to the advection time from the injection well to the pumping well of 18 hours. The advection time of 18 hours is used in the identification of effective porosity together with the longitudinal dispersity in the following part of the paper. 
Vietnam Journal of Earth Sciences, 39(1), 58-75
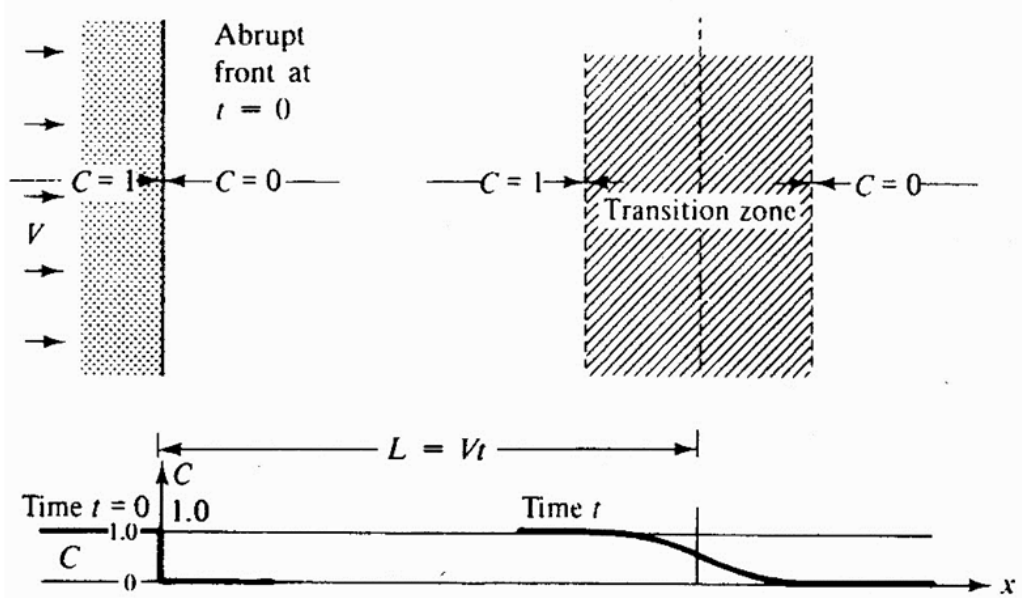

(a)

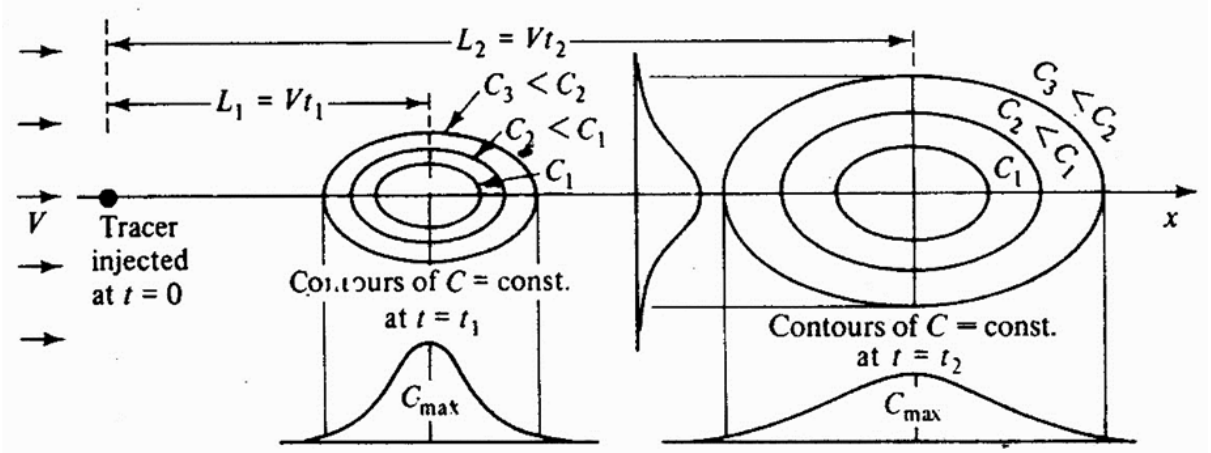

(b)

Figure 8. The role of the effective porosity and hydrodynamic dispersion in the solute transport by GW (Bear and Verruijt, 1987)

\subsection{Solute transport by advection-dispersion}

The partial differential equation describing the solute transport by advection-dispersion in one dimensional space is as follows (Bear and Verruijt, 1987):

$$
D_{x} \frac{\partial^{2} C}{\partial x^{2}}-U_{x} \frac{\partial C}{\partial x}=R \frac{\partial C}{\partial t}
$$

In which: $D_{x}$, is hydrodynamic dispersion coefficient $\left(\mathrm{L}^{2} / \mathrm{T}\right), C$ is the $\mathrm{GW}$ solute concentration $\left(\mathrm{M} / \mathrm{L}^{3}\right), U_{x}\left(U=V / n_{\text {eff }}\right)$ is the pore velocity $(\mathrm{M} / \mathrm{T}), V$ is the Darcy velocity; $n_{\text {eff }}$ is the effective porosity; $R$ is retardation coefficient; $t$ is time (T);.
The hydrodynamic dispersion coefficient can be given as follows (Bear J. and Verruijt A., 1987):

$$
D_{x}=D^{\prime}{ }_{x}+D_{d}^{*} ; D_{x}^{\prime}=a_{L} U
$$

in which: $D_{x}^{\prime}$ is mechanical dispersion $\left(\mathrm{L}^{2} / \mathrm{T}\right)$; $D^{*}{ }_{d}$ is molecular dispersion coefficient of the porous medium $\left(\mathrm{L}^{2} / \mathrm{T}\right) ; a_{L}$ is the longitudinal dispersivity (L).

Eq.(5) may have a unique solution if appropriate initial and boundary conditions are prescribed.

The initial condition is the distribution of the solute concentration $C_{0}$ over the whole model area at the initial time $t=t_{0}$ : 
Tong Ngoc Thanh, et al./Vietnam Journal of Earth Sciences 39 (2017)

$$
C=C_{o}(x)
$$

The boundary condition may be as the follows:

Boundary of specified solute concentration (Dirichlet boundary):

$$
C=C_{c} \text { on boundary } \Gamma_{c}
$$

Boundary of specified concentration gradient (Neumann boundary):

$$
\frac{\partial C}{\partial \mathbf{n}}=q \text { on boundary } \Gamma_{q_{c}}
$$

Boundary of specified solute mass rate (Cauchi boundary):

$V_{n} C-D_{n} \frac{\partial C}{\partial n}=\frac{V_{0} C_{v}}{n}$ on boundary $\Gamma_{q_{v}}$

in which: $V_{0}$ is Darcy velocity $(\mathrm{L} / \mathrm{T}) ; C_{v}$ is $\mathrm{GW}$ solute concentration $\left(\mathrm{M} / \mathrm{L}^{3}\right) ; n$ is the normal vector to the boundary line.

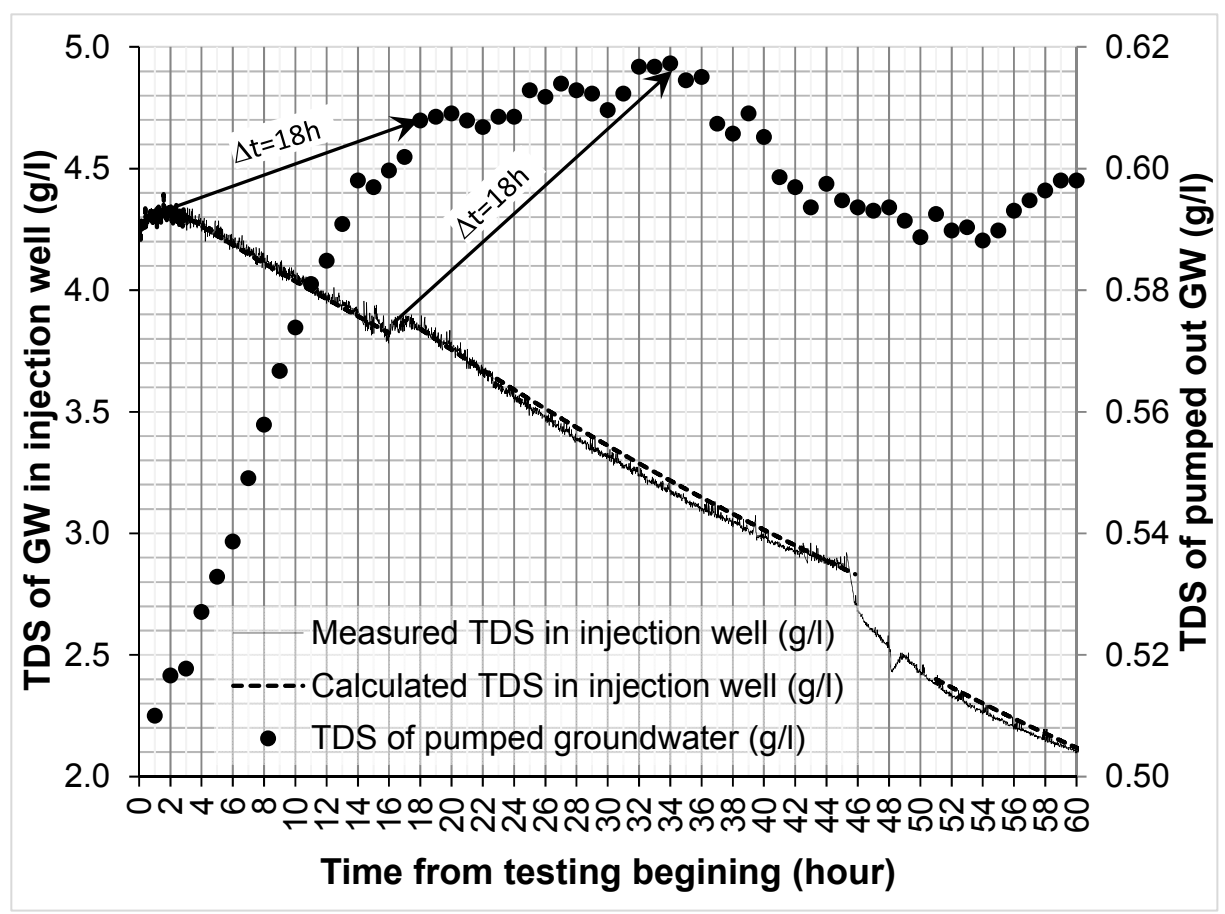

Figure 9. TDS breakthrough curves of GW in injection and pumping wells

\subsection{Solution by the finite element method}

Dividing the model area into finite elements and applying the Galernkin FEM with linear shape functions and central time scheme with time step $\Delta t_{n}$ (Zienkiewicz and Morgan, 1983; Nguyen Van Hoang, 2016) the following system of linear equations can be obtained:

$$
\left(\frac{1}{2}[A]+\frac{[B]}{\Delta t_{n}}\right)\left\{C_{n+1}\right\}+\left(\frac{1}{2}[A]-\frac{[B]}{\Delta t_{n}}\right)\left\{C_{n}\right\}=\frac{1}{2}\left\{F_{n}\right\}+\frac{1}{2}\left\{F_{n+1}\right\}
$$

in which $[A]$ and $[B]$ are rectangular matrices $M \times M ;\{C\},\left\{F_{n}\right\}$ and $\left\{F_{n+1}\right\}$ are column matrices $M$. The concentration at time step $n+1$ is $\left\{C_{n+1}\right\}$ and determined from the concentration $\left\{C_{n}\right\}$ at the previous time step $n$.
In order to ensure the required accuracy of the numerical results, the time step and element size must meet the following criteria on Peclet Courant numbers as follows (Huyakorn and Pinder, 1983): 
Vietnam Journal of Earth Sciences, 39(1), 58-75

$$
\text { Peclet number: } P e=\frac{V_{x, i} \Delta x_{i}}{D_{x, i}} \leq 2 \text {; Courant number: } C r=\frac{V_{x, i} \Delta t}{\Delta x_{i}} \leq 1
$$

The GW flow and solute transport FE modeling software prepared within the NOFOSTED research project headed by Nguyen Van Hoang (2014-2017) is used in this work. Within the software package of the project, the regional $\mathrm{GW}$ flow simulation for the downstream of Tri An reservoir was applied in 2012 (Nguyen Van Hoang et al., 2012) to study the GW level regime under the reservoir operation, the solute transport by GW validation and accuracy comparison have been presented through standard analytical problems (Nguyen Van Hoang et al., 2014), and the GW infiltration simulation to study the rainfall recharge to $\mathrm{GW}$ in Hung Yen province by Nguyen Van Hoang and Nguyen

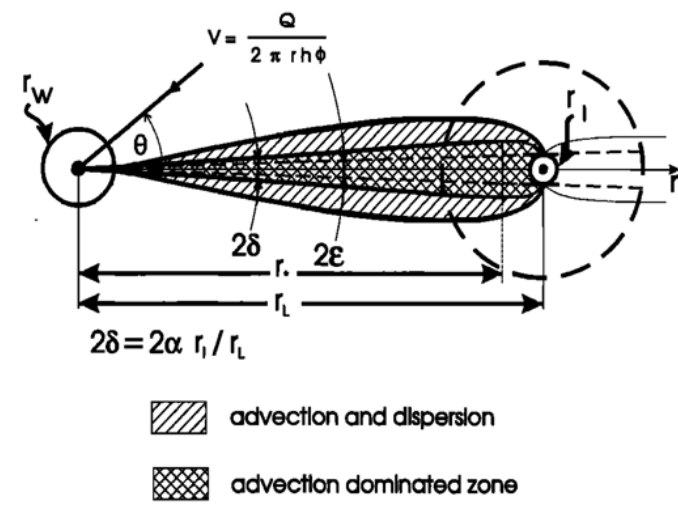

(a)
Duc Roi (2015), and the GW solute transport simulation was applied to study the characteristics of the solute transport in twodimensional aquifer cross section under different boundary conditions by Nguyen Van Hoang et al. (2016). The GW solute transport FEM program had been embedded with the algorithm of the method of least squares for parameter identification.

\subsection{Numerical modeling for determination of effective porosity and longitudinal dispersivity}

The zones of the main mechanism of solute transport by GW in between the injection and pumping wells is presented in Figure 10 as by Zlotnik (1996).

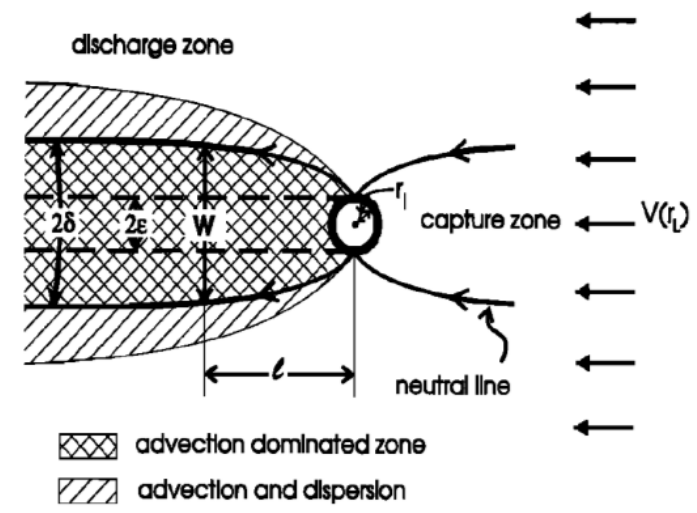

(b)

Figure 10. Two zones of main mechanism of solute transport between injection and pumping wells (Zlotnik, 1996)

The width $W$ of the capture zone in the upstream of the injection well and the supply zone to the pumping well by Drost et al., (1968) has a value $W \leq 4 r_{I}$ (Figure 10b) if the permeability of the disturbed aquifer around the injection well is smaller the natural aquifer permeability. This always happens in the practice of drilling and construction of $\mathrm{GW}$ monitoring wells. Therefore, for the testing scheme in Nghiem Xuyen, Thuong Tin, Hanoi city, the maximal width of the solute transport zone is about $0.2 \mathrm{~m}$, which is significantly smaller than the distance between the injection and pumping wells. Therefore, onedimensional modelling of the solute transport may be applied for the purpose of transport parameter identification.

In the testing the solute concentration of pumped GW is measured, however, the modelling can provide the GW concentration only at the edge of the pumping well screen. As a rule, the concentration in pumped out $\mathrm{GW}$ is 
exactly linearly proportional to the solute concentration right outside the pumping well. Therefore, relative solute concentrations shown in Figure 9 for the pumped out GW and GW right outside the pumping well may be used for the purpose of parameter identification. Theoretically, the two relative solute concentrations are identical. Taking notations of the solute concentration of pumped out $\mathrm{GW}$ as $C_{p u m}$ with the maximal value $C_{p u m m a x}$ and minimal $C_{\text {pummin }}$ (Figure 11a), and correspondingly those for the solute concentration

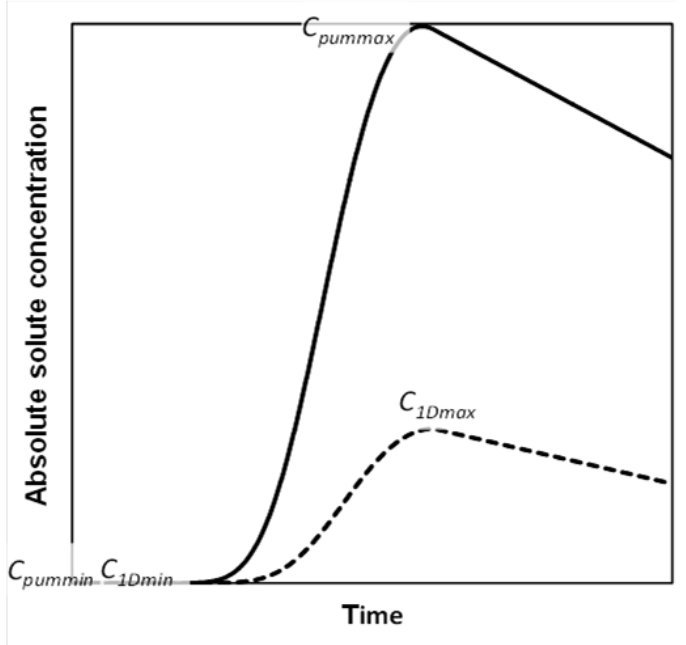

(a) at the edge of the pumping well in model $C_{I D \max }$ and $C_{I D \min }$, the relative solute concentration in the pumped out GW and GW in the edge of the pumping well are as follows:

$$
C=\frac{C_{\text {pum }}-C_{\text {pummin }}}{C_{\text {pummax }}-C_{\text {pumnin }}} ; \quad C=\frac{C_{1 D}-C_{1 D \text { min }}}{C_{1 D \text { max }}-C_{1 D \text { min }}}
$$

The transformation of absolute solute concentration (Figure 11a) into relative solute concentration (Figure 11b) is illustrated in Figure 11.

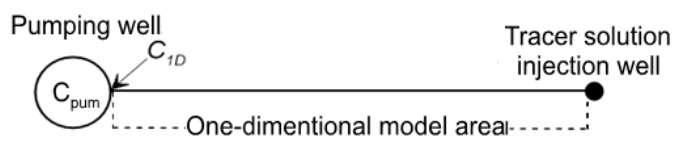

$\mathrm{C}_{\text {pum }}$ - Tracer concentration of $\mathrm{GW}$ in pumping well

$C_{10}$ - Tracer concentration of $\mathrm{GW}$ in the pumping well screen

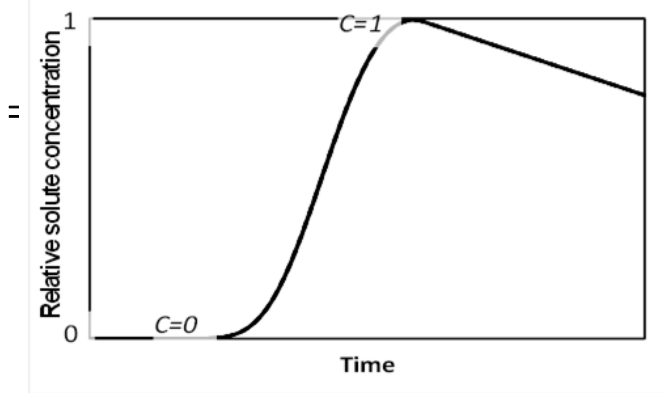

(b)

Figure 11. The transformation of solute concentration into relative solute concentration

\subsection{Parameter identification results}

Since the Pleistocene aquifer consists of coarse sands, gravels and pebbles the adsorption or desorption of salt is negligible, i.e. the retardation coefficient $R$ in Eq.(5) can be admitted to be 1 .

Using the following equation for determining the effective porosity (Nguyen Van Hoang, 2016) with the arrival time of 18 hours determined in Figure 9 the effective porosity of the testing aquifer can be determined:

$$
t=\left.\frac{m n_{\text {eff }}}{0.3179 Q} r^{2}\right|_{r_{e l l}} ^{r} \Rightarrow n_{\text {eff }}=\left.\frac{0.3179 Q t}{m r^{2}}\right|_{r_{\text {vell }}} ^{r}
$$

With $\mathrm{Q}=2,592 \mathrm{~m}^{3} /$ day, $\mathrm{r}=8 \mathrm{~m}$ and $\mathrm{m}=12.7 \mathrm{~m}$ (Figure 5) it gave neff $=0.76032$, which cannot be accepted as the porosity of the aquifer.

In accordance with the results of pumping testing of the lower Pleistocene qp1 (Tong Thanh Tung, 2015) then the lower Pleistocene aquifer qp1 is a leaky confined aquifer thanks to the contact with the Neogene N2 fractured sandstone and conglomerate aquifer below. For a leaky confined aquifer, the early pumping data are entirely representing the confined aquifer without leakage effect (Fetter, 2001). As the data on the Figure 12 shows, during the first 60 minutes of pumping the 
slope of the time-drawdown curve is equal to 0.36 which is two times greater than that of the average of the whole pumping time. It means that the leakage from the Neogen aquifer provides $50 \%$ of the pumping rate for the late pumping time. Therefore, the pumping rate Q in the Eq.(14) should be decreased to the half value, which would result in the effective porosity of 0.3902 . The effective porosity shall be further refined together with the longitudinal dispersivity identification by the FE modeling.

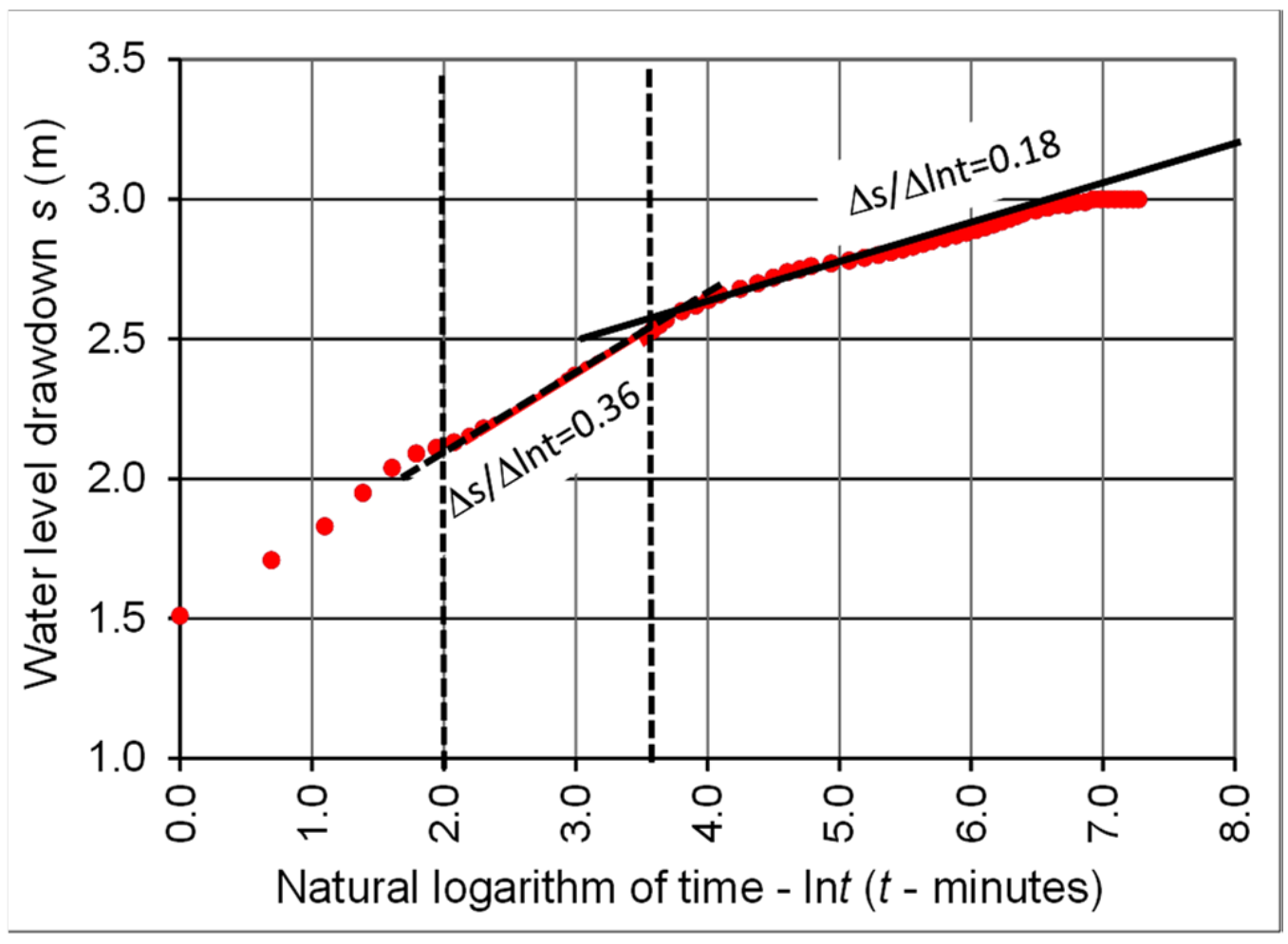

Figure 12. Time-drawdown for pumping well QS-5A 13 (Tong Thanh Tung, 2015)

Effective porosity and longitudinal dispersivity have been identified and refined by the algorithm of least squares between the observed and model concentrations. The FE modeling of the advection-dispersion solute transport by GW was provided by the Governmental project supported by NAFOSTEDMOST (Nguyen Van Hoang, 2014-2017). The input range of the effective porosity is $0.20 \div 0.40$ and of the longitudinal dispersivity is $1.0 \mathrm{~m} \div 3.4 \mathrm{~m}$ had given the effective porosity of 0.32 and longitudinal dispersivity of $2.50 \mathrm{~m}$ which are corresponding to the least squares 0.00119 . The detailed results of the identification modeling are presented in Table 2 and Figure 13. 
Tong Ngoc Thanh, et al./Vietnam Journal of Earth Sciences 39 (2017)

Table 2. The average least squares and corresponding effective porosity and longitudinal dispersivity

\begin{tabular}{|c|c|c|c|c|c|c|c|c|}
\hline $\mathrm{n}_{\text {eff }}$ & $a_{L}(m)$ & Average least squares & $\mathrm{n}_{\text {eff }}$ & $\underline{a_{L}(m)}$ & Average least squares & $\mathrm{n}_{\text {eff }}$ & $\underline{\mathrm{a}_{\mathrm{L}}(\mathrm{m})}$ & Average least squares \\
\hline 0.26 & 1.80 & 0.00373 & 0.29 & 2.70 & 0.00255 & 0.33 & $\overline{2.30}$ & 0.00157 \\
\hline 0.26 & 1.90 & 0.00401 & 0.29 & 2.80 & 0.00273 & 0.33 & 2.40 & 0.00143 \\
\hline 0.26 & 2.00 & 0.00429 & 0.29 & 2.90 & 0.00292 & 0.33 & 2.50 & 0.00133 \\
\hline 0.26 & 2.10 & 0.00456 & 0.29 & 3.00 & 0.00310 & 0.33 & 2.60 & 0.00126 \\
\hline 0.26 & 2.20 & 0.00484 & 0.30 & 1.80 & 0.00129 & 0.33 & 2.70 & 0.00123 \\
\hline 0.26 & 2.30 & 0.00511 & 0.30 & 1.90 & 0.00123 & 0.33 & 2.80 & 0.00121 \\
\hline 0.26 & 2.40 & 0.00538 & 0.30 & 2.00 & 0.00122 & 0.33 & 2.90 & 0.00122 \\
\hline 0.26 & 2.50 & 0.00564 & 0.30 & 2.10 & 0.00125 & 0.33 & 3.00 & 0.00124 \\
\hline 0.26 & 2.60 & 0.00589 & 0.30 & 2.20 & 0.00131 & 0.34 & 1.80 & 0.00446 \\
\hline 0.26 & 2.70 & 0.00614 & 0.30 & 2.30 & 0.00140 & 0.34 & 1.90 & 0.00379 \\
\hline 0.26 & 2.80 & 0.00638 & 0.30 & 2.40 & 0.00150 & 0.34 & 2.00 & 0.00324 \\
\hline 0.26 & 2.90 & 0.00661 & 0.30 & 2.50 & 0.00162 & 0.34 & 2.10 & 0.00279 \\
\hline 0.26 & 3.00 & 0.00683 & 0.30 & 2.60 & 0.00174 & 0.34 & 2.20 & 0.00241 \\
\hline 0.27 & 1.80 & 0.00252 & 0.30 & 2.70 & 0.00188 & 0.34 & 2.30 & 0.00211 \\
\hline 0.27 & 1.90 & 0.00275 & 0.30 & 2.80 & 0.00202 & 0.34 & 2.40 & 0.00187 \\
\hline 0.27 & 2.00 & 0.00298 & 0.30 & 2.90 & 0.00217 & 0.34 & 2.50 & 0.00168 \\
\hline 0.27 & 2.10 & 0.00322 & 0.30 & 3.00 & 0.00233 & 0.34 & 2.60 & 0.00153 \\
\hline 0.27 & 2.20 & 0.00346 & 0.31 & 1.80 & 0.00161 & 0.34 & 2.70 & 0.00142 \\
\hline 0.27 & 2.30 & 0.00371 & 0.31 & 1.90 & 0.00142 & 0.34 & 2.80 & 0.00134 \\
\hline 0.27 & 2.40 & 0.00395 & 0.31 & 2.00 & 0.00129 & 0.34 & 2.90 & 0.00128 \\
\hline 0.27 & 2.50 & 0.00419 & 0.31 & 2.10 & 0.00122 & 0.34 & 3.00 & 0.00125 \\
\hline 0.27 & 2.60 & 0.00442 & 0.31 & 2.20 & 0.00119 & 0.35 & 1.80 & 0.00598 \\
\hline 0.27 & 2.70 & 0.00466 & 0.31 & 2.30 & 0.00119 & 0.35 & 1.90 & 0.00513 \\
\hline 0.27 & 2.80 & 0.00488 & 0.31 & 2.40 & 0.00123 & 0.35 & 2.00 & 0.00441 \\
\hline 0.27 & 2.90 & 0.00511 & 0.31 & 2.50 & 0.00128 & 0.35 & 2.10 & 0.00380 \\
\hline 0.27 & 3.00 & 0.00533 & 0.31 & 2.60 & 0.00136 & 0.35 & 2.20 & 0.00330 \\
\hline 0.28 & 1.80 & 0.00172 & 0.31 & 2.70 & 0.00145 & 0.35 & 2.30 & 0.00288 \\
\hline 0.28 & 1.90 & 0.00187 & 0.31 & 2.80 & 0.00155 & 0.35 & 2.40 & 0.00253 \\
\hline 0.28 & 2.00 & 0.00204 & 0.31 & 2.90 & 0.00166 & 0.35 & 2.50 & 0.00224 \\
\hline 0.28 & 2.10 & 0.00223 & 0.31 & 3.00 & 0.00177 & 0.35 & 2.60 & 0.00200 \\
\hline 0.28 & 2.20 & 0.00243 & 0.32 & 1.80 & 0.00226 & 0.35 & 2.70 & 0.00180 \\
\hline 0.28 & 2.30 & 0.00264 & 0.32 & 1.90 & 0.00192 & 0.35 & 2.80 & 0.00164 \\
\hline 0.28 & 2.40 & 0.00285 & 0.32 & 2.00 & 0.00167 & 0.35 & 2.90 & 0.00152 \\
\hline 0.28 & 2.50 & 0.00306 & 0.32 & 2.10 & 0.00148 & 0.35 & 3.00 & 0.00143 \\
\hline 0.28 & 2.60 & 0.00327 & 0.32 & 2.20 & 0.00135 & 0.36 & 1.80 & 0.00775 \\
\hline 0.28 & 2.70 & 0.00348 & 0.32 & 2.30 & 0.00126 & 0.36 & 1.90 & 0.00670 \\
\hline 0.28 & 2.80 & 0.00369 & 0.32 & 2.40 & 0.00121 & 0.36 & 2.00 & 0.00580 \\
\hline 0.28 & 2.90 & 0.00389 & 0.32 & 2.50 & 0.00119 & 0.36 & 2.10 & 0.00504 \\
\hline 0.28 & 3.00 & 0.00410 & 0.32 & 2.60 & 0.00120 & 0.36 & 2.20 & 0.00440 \\
\hline 0.29 & 1.80 & 0.00132 & 0.32 & 2.70 & 0.00123 & 0.36 & 2.30 & 0.00385 \\
\hline 0.29 & 1.90 & 0.00137 & 0.32 & 2.80 & 0.00127 & 0.36 & 2.40 & 0.00338 \\
\hline 0.29 & 2.00 & 0.00146 & 0.32 & 2.90 & 0.00133 & 0.36 & 2.50 & 0.00298 \\
\hline 0.29 & 2.10 & 0.00158 & 0.32 & 3.00 & 0.00141 & 0.36 & 2.60 & 0.00264 \\
\hline 0.29 & 2.20 & 0.00171 & 0.33 & 1.80 & 0.00322 & 0.36 & 2.70 & 0.00236 \\
\hline 0.29 & 2.30 & 0.00186 & 0.33 & 1.90 & 0.00272 & 0.36 & 2.80 & 0.00213 \\
\hline 0.29 & 2.40 & 0.00203 & 0.33 & 2.00 & 0.00232 & 0.36 & 2.90 & 0.00193 \\
\hline 0.29 & 2.50 & 0.00220 & 0.33 & 2.10 & 0.00200 & 0.36 & 3.00 & 0.00177 \\
\hline 0.29 & 2.60 & 0.00237 & 0.33 & 2.20 & 0.00176 & & & \\
\hline
\end{tabular}




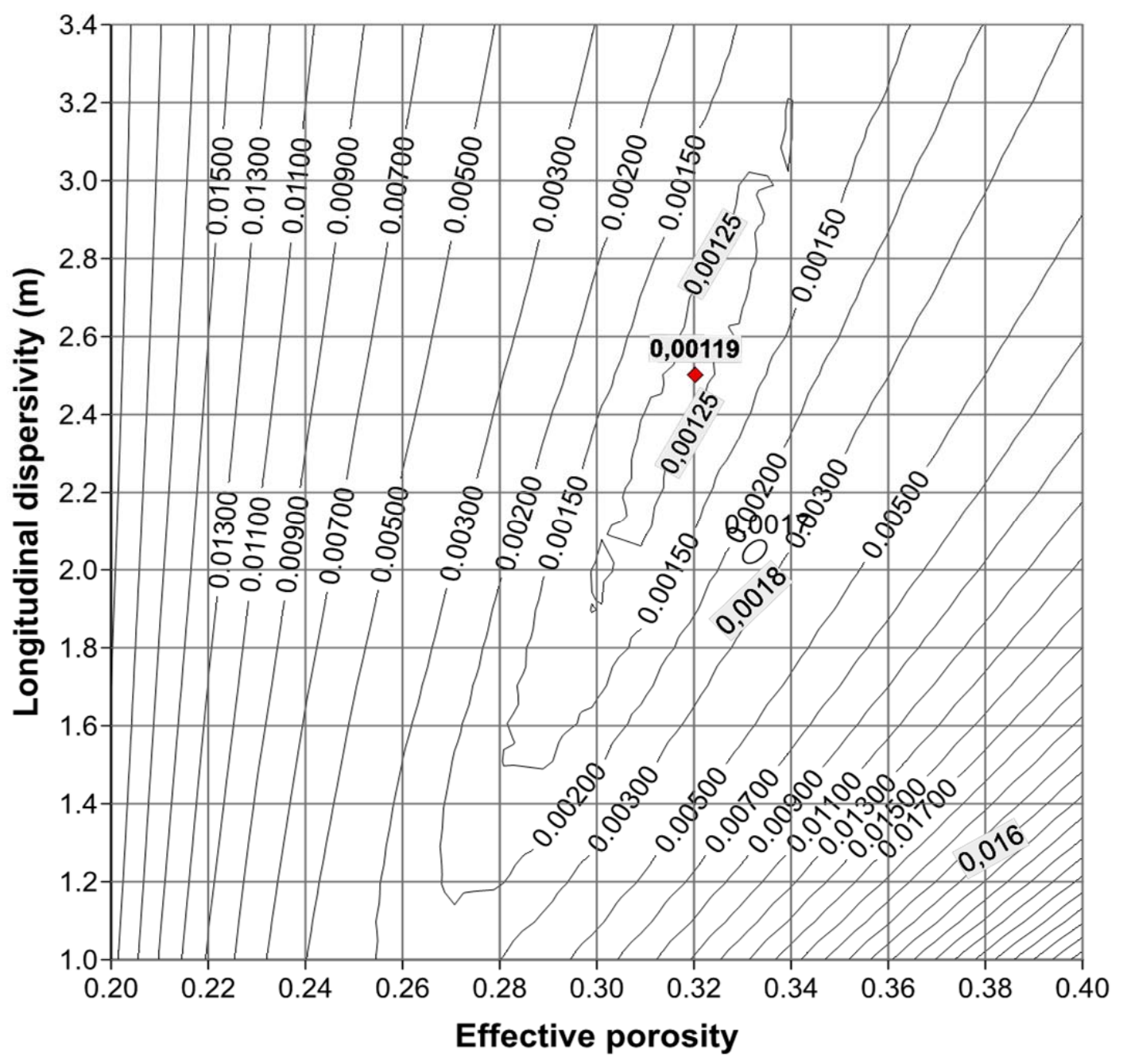

Figure 13. The average least squares and corresponding effective porosity and longitudinal dispersivity

The absolute and relative solute concentrations in the pumped $\mathrm{GW}$ and at the pumping well screen corresponding to the identified effective porosity and longitudinal dispersivity which gave minimal least squares are presented in Figure 14 and 15, respectively. The effective porosity is 0.32 and the longitudinal dispersivity is $2.5 \mathrm{~m}$ (which gives hydrodynamic dispersion from $\mathrm{D}=250 \mathrm{~m}^{2} /$ day at the pumping well screen and to $\mathrm{D}=18 \mathrm{~m}^{2} /$ day at the injection well screen) with the minimal average least squares of 0.00119 , which is corresponding to average difference between the observed and model concentration of $0.0355 \mathrm{~g} / 1$ while the concentration range is $0 \mathrm{~g} / 1 \div 1 \mathrm{~g} / \mathrm{l}$. The model result shows that the maximal solute concentration at the pumping well screen is 6.1 times greater than the solute concentration of the pumped water (Figure 14). 
Tong Ngoc Thanh, et al./Vietnam Journal of Earth Sciences 39 (2017)

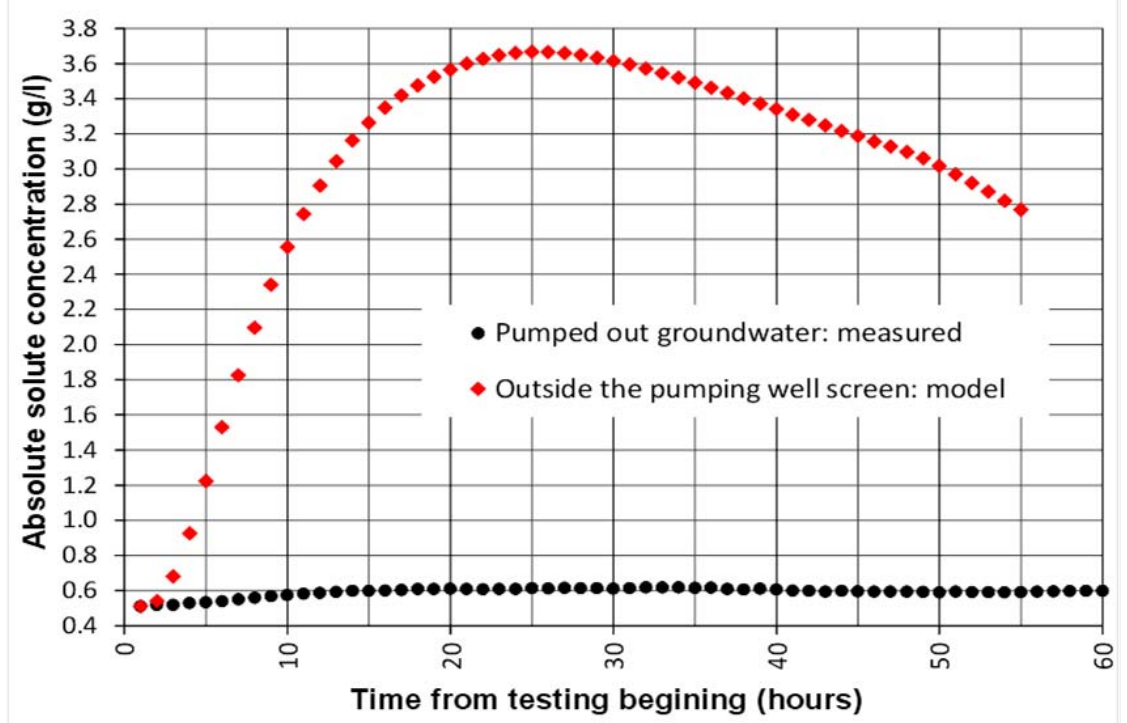

Figure 14. Absolute solute concentration in the pumped GW and at the pumping well screen side corresponding to the case of minimal least squares

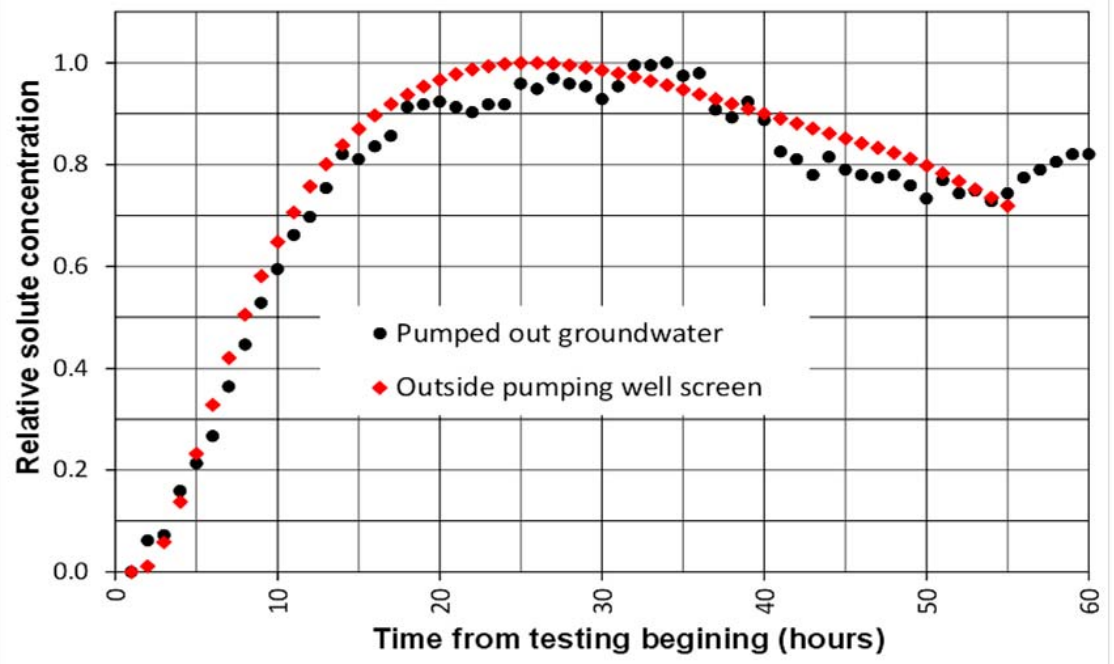

Figure 15. Relative solute concentration in the pumped GW and at the pumping well screen corresponding to the minimal least squares

\section{Discussions}

Through the interpretation of the GW tracer injection testing data and analysis of the solute transport parameters of the lower Pleistocene aquifer qp1 in the southern part of Hanoi city, the following discussions can be addressed:

In accordance to Aravin and Numerov (1948) (Polubarinova-Kotrina, 1977) the total porosity of gravels with grain sizes from $2 \mathrm{~mm}$ to $20 \mathrm{~mm}$ is $0.30 \div 0.40$ and of sands of grain 
sizes from $0.5 \mathrm{~mm}$ to $2 \mathrm{~mm}$ is $0.30 \div 0.45$. Also in accordance to Meinzer (1923), Davis (1969), Cohen (1965), MacCary and Lambert (1962) (Fetter, 2001) the total porosity of well-sorted gravels is in the range $0.25 \div 0.50$ and that of the gravels is $0.20 \div 0.35$. For the sands, gravels, and pebbles, the effective porosity is almost the same as the total porosity (Fetter, 2001) since there is almost no death pores in such loose formation (Bear and Verruijt, 1987). Therefore, the identified effective porosity equal to 0.32 obtained in this work is within the possible porosity range for sands, gravels, and pebbles of the lower Pleistocene aquifer qp1, without any contradiction.

During the tracer injection, some instabilities of the injection (variable injection rates or even with some discontinuity of injection) did occur. The effective porosity may be calculated through such discontinuity points along with other relevant parameters (pumping rate, aquifer thickness, and the distance between the pumping and injection wells). However, for incompletely single confined aquifer (for example, for leaky confined aquifer), such application definitely brings to the wrong value. A careful pumping data interpretation and analysis need to be carried out in order to apply the effective porosity determination in the appropriate way;

The identified longitudinal dispersivity value of $2.50 \mathrm{~m}$ for the lower Pleistocene aquifer $\mathrm{qp} 1$ is a rather high value in compare to the characteristic grain size of the aquifer (in accordance to Bear and Verruijt (1987), the longitudinal dispersivity is an order of the characteristic grain size). However, in the practice, there are a lot of experimental data showing this large value trend of the longitudinal dispersivity. Besides, in accordance to some authors, the hydrodynamic dispersion is exponentially proportional to the dispersivity, so that the actual dispersivity may be lower than this identified value;

The flow distortion coefficient $\alpha_{\mathrm{w}}$ is an important parameter in the data interpretation and analysis of GW solute transport parameters, and at the same time plays important role in the efficiency of the tracer injection testing. Therefore, appropriate drilling and GW well construction technique should be used in order to ensure the maximal well efficiency.

\section{Conclusions}

If only the solute concentration of GW inside the pumping well is measured, the GW solute transport parameters can only be determined based on the relative solute concentrations;

Only numerical modeling is capable of determining the GW solute transport parameters (effective porosity and dispersivity) of the aquifer under tracer injection testing;

The method of the least squares may be one of the efficient methods for solving this kind of parameter identification;

At the testing site in Nghiem Xuyen Thuong Tin - Hanoi, the lower Pleistocene aquifer qp1 has effective porosity of 0.32 and longitudinal dispersivity of $2.5 \mathrm{~m}$ (which gives hydrodynamic dispersion from $\mathrm{D}=250 \mathrm{~m}^{2} /$ day at the pumping well screen and to $\mathrm{D}=18 \mathrm{~m}^{2} /$ day at the injection well screen);

The flow distortion coefficient $\alpha \mathrm{w}$ (the ratio between the flow through the monitoring well section and the flow through the same section without monitoring well) of the monitoring well varies from 18.66 (early pumping time) to 10.76 (late pumping time).

A stable solute injection is suggested during the whole testing time in order to have a good temporal concentration without any further data processing which may bring to some certain inaccuracy;

Some monitoring wells along the section line connecting the pumping and injection wells are recommended to be installed for monitoring the solute concentration;

An exact determination of the aquifer thickness and leakage parameters for the aquifer are required in order to be able to analytically determine the effective porosity; 
Tong Ngoc Thanh, et al./Vietnam Journal of Earth Sciences 39 (2017)

It is strictly required that the pumping rate be constant over the entire testing time;

Ensure the maximal well efficiency of the tracer injection well.

\section{Acknowledgements}

This work had been jointly completed within the framework of the Governmental project: "Study on the finite element modeling software for simulation of groundwater flow and solute transport by groundwaterapplication to the aquifer in the Central plain of Vietnam" codded ĐT.NCCB-ĐHUD.2012G/04 supported by NAFOSTED-MOST and the project "Groundwater protection in large cities (city: Hanoi)" by Vietnam National Center for Water Resources Planning and Investigation-MoNRE.

\section{References}

Bear J. and Verruijt A., 1987. Modeling groundwater flow and pollution, D. Reidel Publishing Company, Dordrecht, Holand, 414pp.

Brouyère S. 2008. Modeling tracer injection and wellaquifer interactions: a new mathematical and numerical approach. Water Resour. Res, 39(3), 1070-1075.

Drost, W., D. Klotz, A. Koch, H. Moser, F. Neumaier, and W. Rauert, 1968. Point dilution methods of investigating ground water flow by means of radioisotopes. Water Resour. Res., 4(1), 125-146.

Fetter C.W., 2001. Applied Hydrogeology. Prentice Hall Inc. New Jersey 07458, 598pp.

Hall, S.H., 1996. Practical single-well tracer methods for aquifer testing, In: Tenth National Outdoor Action Conference and Exposition, National Groundwater Association, Colombus, Ohio, USA, 11pp.

Huyakorn P.S., and Pinder G. F., 1983. Computational Methods in Subsurface Flow. Academic Press, New York, 473pp.

Nguyen Van Hoang, 2016. Modeling of pollutant transport in water environment. Vietnam Academy of Science and Technology Publishers, 201pp.

Nguyen Van Hoang (project head) (2014-2017). Science and Technology Proposal: Study on the finite element modeling software for simulation of groundwater flow and solute transport by groundwater- application to aquifer in Central plain of Vietnam" codded ĐT.NCCB-ĐHU'D.2012-G/04 supported by NAFOSTED-MOST.

Nguyen Van Hoang, Dinh Van Thuan, Nguyen Duc Roi, Le Duc Luong, 2012. Study on the impact of the Tri An reservoir on its downstream groundwater level regime. Journal of Sciences of Earth, 34(4), 465-476.

Nguyen Van Hoang, Pham Lan Hoa, Le Thanh Tung, 2014. Study on the accuracy of the numerical model-ing of the groundwater movement due to spatial and temporal discretization. Journal of Sciences of Earth, 36(4), 424-431.

Nguyen Van Hoang and Nguyen Duc Roi, 2015. Finite element method in estimation of lag time of rainfall recharge to Holocene groundwater aquifer in Hung Yen province. Journal of Sciences of Earth, 37(4), 355-362.

Nguyen VH., Nguyen TC., Pham LH., Le TT., 2016. Study on the character-istics of salinity transport in 2D cross-section uncon-fined aquifer. Vietnam Journal of Earth Sciences, 38(1), 66-78.

Novakowski, K.S., 1992. An evaluation of boundary conditions for one-dimensional solute transport, 1, Mathematical development. Water Resour. Res., 28(9), 2399-2410.

Polubarinova-Kotrina P. IA., 1977. Theory of Ground-water. Moscow Science Publishers. 664pp.

Tong Thanh Tung, 2015. Specialized report: Interpretation and analysis of aquifer parameters for pumping test at group-well test CHN5 in Nghiem XuyenThuong Tin-Hanoi. Project "Groundwater protection in large cities (city: Hanoi)". Vietnam National Center for Water Resources Planning and InvestigationMoNRE, 16pp.

Trieu Duc Huy (Project head), 2015. Science and Technology Proposal: Groundwater protection in large cities (city: Hanoi) approved by MoNRE Minister in Decision 1557/QD-BTNMT dated 30th Aug. 2013. Vietnam National Center for Water Resources Planning and Investigation-MoNRE.

Vitaly A. Zlotnik and John David Logan, 1996. Boundary Conditions for Convergent Radial Tracer Tests and Effect of Well Bore Mixing Volume. Papers in the Earth and Atmospheric Sciences, 159pp.

Zienkiewicz O. C. and Morgan K., 1983. Finite Elements and Approximation. Academic Press, 328p. 